\title{
Lipid oxidation in biscuits: comparison of different lipid extraction methods
}

\author{
Mariela Patrignani • Paula A. Conforti • \\ Cecilia E. Lupano
}

Received: 3 June 2014/ Accepted: 6 October 2014

(C) Springer Science+Business Media New York 2014

\begin{abstract}
This study was conducted in order to describe a proper method of extraction and quantification of peroxides in a complex matrix as biscuits. Different lipid extraction methods were applied in low lipid biscuits: direct solvent extraction; conventional Soxhlet extraction, the American Association of Cereal Chemists (AACC) method and a modification of the AACC method, in which the heating of the sample was avoided. Furthermore, the quantification method of peroxides was simplified and adapted to samples with low lipid content using easily accessible equipment. Significant differences $(p \leq 0.05)$ were found in the peroxide value of the lipids extracted with different extraction procedures. All the extraction methods performed, except the AACC, were found to be suitable for the determination of peroxides in low lipid biscuits. However, as direct solvent extraction provided a faster and simpler analysis, this method seemed to be the most suitable for peroxide determination in low lipid biscuits.
\end{abstract}

Keywords Lipid oxidation - Biscuit - Lipid extraction method $\cdot$ Ferric thiocyanate assay

\section{Introduction}

The food industry has showed an increasing tendency in developing healthier foods with low levels of sugar and

M. Patrignani · P. A. Conforti · C. E. Lupano $(\bowtie)$

Centre for Research and Development in Food Cryotechnology

(CIDCA), Faculty of Exact Sciences, UNLP - CCT La Plata -

CONICET, 47 and 116, 1900 La Plata, Argentina

e-mail: cel@quimica.unlp.edu.ar

P. A. Conforti

Faculty of Agricultural Sciences and Forestry, UNLP, 60 and

116, 1900 La Plata, Argentina lipids [1-3]. However, these developments should go hand by hand with new analytical methods to determine the food parameters related to the product shelf life.

One of the main facts that decrease the food quality is lipid oxidation [4]. It not only generates unacceptable characteristics for costumers such as unpleasant flavour changes [5, 6] but also diminishes the amount of essential fatty acids [7]. Nowadays there are many analytical methods to measure lipid oxidation in different foods [8]. However, there is not a proper and simple method to determine oxidation in biscuits with low lipid content.

Peroxide determination in a complex matrix as biscuits implies an extraction procedure. This procedure is a critical part of the determination, the use of different methods results in different lipid recoveries and the peroxide value might varied due to differences in the extraction methodology. Literature research showed that many methods include the heating of the samples to extract the lipids [9, 10], although high temperatures might accelerate lipid oxidation [11]. Other methods required large amounts of sample [12] or use high lipid content biscuits [13]. In addition, some authors recommend that an acid treatment should be performed to release lipids from the biscuit matrix or from different ingredients as eggs or milk which could be added to the biscuits [14]. The biscuit matrix consists in a network of protein closely related with lipids and starch, and this structure hinders the contact between the solvent and lipids [15].

Up to the day there is no bibliography available that describes a proper method of extraction and quantification of peroxides in a complex matrix as biscuits.

In the present work, four different lipid extraction methods were applied in low lipid biscuits. Peroxide and free fatty acid determinations were also performed to determine the best extraction technique. 
Moreover, the quantification method of peroxides was simplified and adapted to low samples with low lipid content using only easily accessible equipment.

\section{Materials and methods}

\section{Materials}

Biscuits were prepared with wheat flour (Favorita 000, Molinos Río de la Plata, Buenos Aires, Argentina), corn starch (Maizena, Unilever de Argentina S.A., Buenos Aires), skim milk powder (SanCor, Sunchales, Santa Fe, Argentina), high oleic sunflower oil (Propia, Lezama, Buenos Aires, Argentina), sucrose (Ledesma, Jujuy, Argentina), and baking powder (Royal, Kraft Foods, Argentina).

All ingredients used were food grade and chemicals were analytical grade.

\section{Instrumental}

In the present work, biscuits were prepared using a Philips Cucina mixer (HR 7633, Sao Paulo, Brazil) and an oven (F9M, Ariston, Fabriano, Italy). The water activity was determined using an AquaLab (Series 3 TE device, Decagon Devices, Pullman, Washington). A conventional Soxhlet extractor (which consists in a heat source, a distillation flask, an extractor, a siphon and a condenser) was used to extract lipids. Besides, a magnetic stirrer (IKA Werke GMH \& Co, Staufen Germany), a vortex mixer (VELP Scientifica, Europe), a water bath (Vicking, Buenos Aires, Argentina) and a UV-mini 1240 Spectrophotometer Shimadzu (Kyoto, Japan) were also used to perform the experimental techniques.

\section{Biscuit preparation}

The biscuits were prepared as described in a previous work [16]. The lipid content for the ingredients was provided on the label by the manufacturer. Formulation contained $70 \mathrm{~g}$ of flour, $20 \mathrm{~g}$ of skimmed milk powder, $60 \mathrm{~g}$ of corn starch, $25 \mathrm{~g}$ of sugar, $1.3 \mathrm{~g}$ of baking powder, $20 \mathrm{~g}$ of high oleic sunflower oil and $36.5 \mathrm{ml}$ of tap water.

Solid ingredients were mixed in a kneading Philips Cucina mixer (HR 7633, Sao Paulo, Brazil). The oil was added in three fractions, mixing each time with 3 pulses $(60 \mathrm{rpm})$ of $2 \mathrm{~s}$. Water was added in two fractions mixing each time with 15 pulses $(60 \mathrm{rpm})$ of $2 \mathrm{~s}$. Dough was put into a polyethylene bag and was manually kneaded until clay type dough. Dough pieces were punctured and then cut in rectangles with a pastry cutter $(0.4 \times 2.5 \times 5 \mathrm{~cm})$. Rectangles of dough were placed on a silicon film and baked in an oven (F9M, Ariston, Fabriano, Italy) at $190{ }^{\circ} \mathrm{C}$ for $9.5 \mathrm{~min}$. The oven temperature was registered by means of thermocouples.

Water activity was measured on the biscuits with a water activity meter (AquaLab Series 3 TE device, Decagon Devices, Pullman, Washington) with temperature control. The sample cup of the instrument was filled with the biscuit samples, and water activity was measured by duplicate at $25{ }^{\circ} \mathrm{C}$. The water activity of biscuits was $0.385 \pm 0.004$. A low water activity is important in biscuit production as it inhibits the microbial grow and ensures a prolonged product shelf life [17].

Finally, biscuits were milled, sieved $(500 \mu \mathrm{m})$ and stored at $5{ }^{\circ} \mathrm{C}$ in closed containers protected from light until analysis.

\section{Lipid extraction techniques}

Lipids were extracted from biscuits by four different methods: direct solvent extraction; conventional Soxhlet extraction; acid treatment followed by extraction [18]; and a modified acid treatment. Experimental methods are described below. In all the cases, the lipid content extracted from the sample was determined by weighing.

\section{Direct solvent extraction}

Lipids in biscuits were extracted following the method described by Mildner-Szkudlarz et al. [12]. Milled biscuits $(7.6 \mathrm{~g})$ were placed in a beaker and extracted with $30 \mathrm{ml}$ of petroleum ether (30-65 boiling point). After $30 \mathrm{~min}$ of stirring at ambient conditions the samples were filtered. All the procedure was repeated using $25 \mathrm{ml}$ of solvent.

The solvent fractions were pooled, and the excess of solvent was removed by evaporation at room temperature.

Soxhlet extraction procedure

Approximately $7.6 \mathrm{~g}$ of milled biscuits were accurately weighed onto a filter paper and wrapped. The wrapped sample was transferred to a Soxhlet extractor with a distillation flask containing petroleum ether (30-65 boiling point). The sample was extracted continuously for about $4 \mathrm{~h}$ [19]. The excess of solvent was removed by evaporation at room temperature, and the lipid content was determined by weighing.

Conventional lipid extraction after acid treatment

An acid treatment can convert bound lipids into easily extractable lipid forms [14]. Hence, the American Association of Cereal Chemists (AACC) recommends that fats should be prepared for lipid extraction by and acid treatment [18]. 
In the present work, lipids were extracted from biscuits according to the method described by AACC [18]. This procedure includes the heating of the sample for $30 \mathrm{~min}$ at $75^{\circ} \mathrm{C}$ in a water bath with $10 \mathrm{ml}$ of $\mathrm{HCl}(6.95 \mathrm{~N})$ and the extraction of lipids with petroleum ether (30-65 boiling point).

The excess of solvent was removed by evaporation at room temperature, and the lipid content extracted from the sample was determined by weighing.

Modified lipid extraction after acid treatment

The lipid extraction procedure after acid treatment was performed as previously described, but the heating of the sample was avoided. Instead, the sample was dispersed for 30 min with a magnetic stirrer at room temperature, and then transferred to a graduated tube.

Determination of free fatty acids

Five $\mathrm{ml}$ of isopropyl alcohol were added to the extracted lipids (0.1 g) and stirred until a clear solution was obtained. Free fatty acids were determined by titration with $\mathrm{NaOH}$ $0.1 \mathrm{~N}$ with phenolphthalein as indicator.

\section{Peroxides determination}

Peroxide value was determined in the oil extracted from biscuits using the Ferric thiocyanate method described by the International Dairy Federation (IDF) together with ISO [20] with some modifications. This quantification is based on the capacity of the peroxides to oxidize the ferrous ion $[\mathrm{Fe}(\mathrm{II})]$ to ferric ion [Fe(III)]. Subsequently a coloured complex between the $\mathrm{Fe}$ (III) and thiocyanate is formed. This method was chosen due to the low lipid content of the biscuits analysed in this work [21].

Isopropyl alcohol $(4.95 \mathrm{ml})$ was added to $0.1 \mathrm{~g}$ of extracted lipid and homogenized with a vortex mixer for $15 \mathrm{~s}$. Then, $0.025 \mathrm{ml}$ of a solution of Fe(II) $(0.72 \% \mathrm{w} / \mathrm{v}$ of $\left.\mathrm{Fe}(\mathrm{NH} 4)_{2}\left(\mathrm{SO}_{4}\right)_{2} \cdot 6 \mathrm{H}_{2} \mathrm{O}\right)$ and $0.025 \mathrm{ml}$ of $30 \% \mathrm{w} / \mathrm{v}$ ammonium thiocyanate solution were added. Absorbance was measured at $500 \mathrm{~nm}$, using a UV-mini 1240 Spectrophotometers Shimadzu (Kyoto, Japan). $\mathrm{A} \mathrm{FeCl}_{3}$ solution $(10 \mu \mathrm{g} / \mathrm{ml})$ was used as a standard [20].

The peroxide value was expressed as mmol of oxygen per $\mathrm{kg}$ of oil. All determinations were made at least in duplicate.

\section{Statistical analysis}

Comparison of lipid extraction yield, peroxide level and free fatty acids of lipids extracted with different extraction methods were subjected to an analysis of variance
(ANOVA) at the $5 \%$ level of significance (InfoStat, 2012, Córdoba, Universidad Nacional de Córdoba, Argentina). The least significant differences (LSD) were calculated to compare the means at a level of $95 \%$ using the Fisher test (InfoStat, 2012, Córdoba, Universidad Nacional de Córdoba, Argentina).

\section{Results and discussion}

Comparison of extraction methods

Several methods have been developed for total lipid extraction in different foodstuffs. In the recent years much research has focused on the adaptation of the Soxhlet apparatus and its automation: High-pressure Soxhlet, Automated Soxhlet, Microwave-assisted Soxhlet and Ultrasound-assisted Soxhlet. Nevertheless, working at high pressure complicates the experimental set-up and automatic equipments are relatively high-cost. Perhaps the most successful has been the use of microwaves, as excellent results were obtained in bakery products [22]. However, this method is limited to device availability and the acquisition costs are high [19].

On the other hand, results varied widely among the different extraction methodologies as they result in different lipid recovery [19, 23, 24]. Manirakiza et al. [23] studied the different extraction yields of various food samples with different extraction methods: Soxhlet, RoeseGottlieb, Bligh \& Dyer, and Modified Bligh \& Dyer. They suggested that Soxhlet extraction may be a convenient method for lipid extraction from solid samples (extraction yield: $90-110 \%$ ).

Gas chromatography (GC) is the most often used method for the analysis and quantification of fatty acids. This method offers excellent separations of most naturally occurring fatty acids [25]. However, in the recent years, different chromatographic techniques for lipid quantification were performed, like modern high-performance TLC (HPTLC). HPTLC is an efficient, quantitative method which presents greater separation efficiency than TLC [26] and offers some advantages over HPLC [27]. Moreover, some authors have described good results in triacylglycerol [28] and polar lipid determinations [29] using ultra-performance liquid chromatography (UPLC). This method presents a better resolution and sensibility than HPLC and the separation time is relatively short [29].

The purpose of this study is to describe the lipid extraction recovery in low lipid biscuits by four different techniques. Significant differences were found between the different extraction techniques $(p \leq 0.05)$. The Soxhlet procedure showed the best extraction rate, 


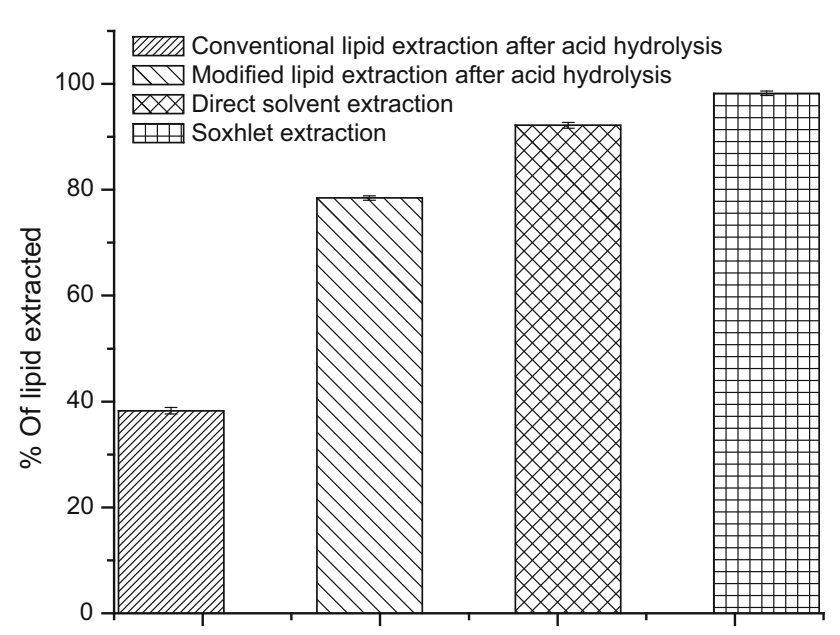

Fig. 1 Percentage of lipids extracted from biscuits with different extraction procedures. Bars show standard deviation

Table 1 Peroxide value and free fatty acid determination of oils extracted from biscuits by four different methods

\begin{tabular}{|c|c|c|}
\hline Extraction procedure & $\begin{array}{l}\text { Peroxide value } \\
\text { (mmol oxygen } / \mathrm{kg} \\
\text { of oil) }\end{array}$ & $\begin{array}{l}\text { Free fatty acid (g } \\
\text { of oleic acid/g of } \\
\text { oil) }\end{array}$ \\
\hline $\begin{array}{l}\text { Conventional lipid } \\
\text { extraction after acidic } \\
\text { treatment }\end{array}$ & $0.38^{\mathrm{a}}$ & $0.07^{\mathrm{a}}$ \\
\hline $\begin{array}{l}\text { Modified lipid extraction } \\
\text { after acidic treatment }\end{array}$ & $0.25^{\mathrm{a}, \mathrm{b}}$ & $0.04^{\mathrm{b}}$ \\
\hline Direct solvent extraction & $0.15^{\mathrm{b}}$ & $0.01^{\mathrm{c}}$ \\
\hline Soxhlet extraction & $0.07^{\mathrm{c}}$ & $0.01^{\mathrm{c}}$ \\
\hline
\end{tabular}

Values followed by the same letter in the same column are not different at a significance level of $5 \%$

followed by the direct solvent extraction procedure. In the Soxhlet procedure, lipids are extracted semicontinuously at the boiling point of the solvent. As a result, the contact time between the sample and the fresh solvent is higher than in other methods. The methods which implied an acid treatment before extraction showed the least extraction percentages (Fig. 1). Similar results were reported by Ruiz- Samblas et al. [30] who optimized a pressurised liquid extraction method for extraction and quantification of total fat in bakery products (extraction rate $98.2 \pm 6.9$ ).

On the other hand, the lowest extraction rate was obtained when the conventional lipid extraction after acid treatment was performed. The evidence suggests that the acidic $\mathrm{pH}$ used might generate aggregates which could decrease the amount of lipid extracted [31]. Furthermore, the high temperatures used during the AACC extraction method seemed to promote the aggregate generation; as a result, a lower extraction rate was obtained.
Free fatty acid determination

In an attempt to analyze the effect that the different extraction techniques have over the lipids, the free fatty acid content was determined. Significant differences were found in the free fatty acid content of the lipids extracted with different extraction procedures $(p \leq 0.05)$ (Table 1).

The present results indicate that Soxhlet and direct solvent extraction did not modify the lipid structure. On the other hand, higher free fatty acid content was obtained in the methods in which acid was used. It is already known that acidic $\mathrm{pH}$ values can cause the hydrolysis of lipids [31]. Besides, as can be seen in Table 1, when the method described by the AACC [18] was performed, it was evident that lipid hydrolysis increased; probably because of the high temperature used.

Peroxides determination

A proper measurement of lipid oxidation is still a challenging task; several methodologies have been implemented for determining both primary and secondary oxidation products. Among the different methods proposed for the analysis of peroxides, iodometry has been the most widespread method due to the simplicity of the experimental procedure and low cost [32]. This method is applicable to all normal fats, but it is highly empirical and slight variations in the methodology could lead to variations in the results. Besides this technique require ten times more sample than spectroscopy methods [33].

On the other hand, chromatographic techniques are more accurate, sensible and specific for the determination of hydroperoxides. High-performance liquid chromatography (HPLC) is highly sensitive and pretty versatile, but sample preparation is tedious and the data processing is laborious. Gas chromatography coupled to mass spectrometry (GC-MS) can also be used for the analysis of lipid hydroperoxides, but due to their thermolability, previous reduction of the hydroperoxides is needed. This fact, along with the prior lipid extraction and derivatization step, makes it a time-consuming and technically difficult method. Moreover, these methods usually require meticulous experimental work and the cost is high [21, 33].

Spectroscopic methods are rather simple and reliable when carried out under standardized conditions. Most of these methods consist in the oxidation of $\mathrm{Fe}$ (II) to $\mathrm{Fe}$ (III) mediated by hydroperoxides, in the presence of tyocianate or xylenol orange (FOX), they form complexes with the ferric ion, giving maximum absorbance peaks at 500 and $560 \mathrm{~nm}$, respectively. This methods are low cost and do not require high sample amounts (0.01-0.3 $\mathrm{g}$ of oil sample) $[21,33]$. Nevertheless, spectroscopic assays do not lack of complications: the spontaneous oxidation of Fe(II) by the 
oxygen present in the air or in the solvent and the high amount of solvent needed are some of the most important limitations. Besides, the curve for iron concentration versus absorbance for the FOX method is not linear in wide ranges of $\mathrm{Fe}(\mathrm{III})$ [34, 35].

The sensitivity of the spectroscopic methods could be modified by an appropriate solvent selection [36]. Several authors have tried to find a suitable solvent for the ferric thiocyanate assay. Shanatha and Decker (1994) [34] recommended a mixture of chloroform-methanol. But it was found that some bottles of chloroform led to high spectrophotometric readings in blank samples [30] while methanol could decrease the amount of Fe(III) formed [37]. Besides, for ecological reasons, the International Dairy Federation suggested a solvent prepared with methanol, 1 -decanol and $n$-hexane, but it has been reported to present a bad smell [20]. Previous works have suggested the use of isopropanol better than the mixture of chloroform and methanol for extraction procedures [38]. Considering this facts, the solvent selected was isopropanol. This solvent is relatively nontoxic in laboratory usage and does not present unpleasant odours.

Some authors have indicated that the presence of oxygen in the solvent may lead to high analytical results [39]. However, because of the low solubility of oxygen in isopropanol [40], deoxygenation in this case was unnecessary.

Moreover, the extinction coefficient of the red $\mathrm{Fe}(\mathrm{III})$ thiocyanate complex in isopropanol, 0.062 units per microgram of $\mathrm{Fe}(\mathrm{III})$, was higher than the one reported previously in the methanol/1-decanol $/ n$-hexane mixture (0.028 extinction units) [20].

Other authors used a solution of $\mathrm{FeCl}_{2}$ prepared in situ from $\mathrm{BaCl}_{2} \cdot 2 \mathrm{H}_{2} \mathrm{O}$ and $\mathrm{FeSO}_{4} \cdot 7 \mathrm{H}_{2} \mathrm{O}$ [29]. But the preparation procedure is time consuming and the solution cannot be stored for more than a week [20]. In addition, Fe(II) oxidation during the determination may lead to high values of the blank solution [34]. Therefore, a freshly prepared $\mathrm{Fe}\left(\mathrm{NH}_{4}\right)_{2}\left(\mathrm{SO}_{4}\right)_{2} \cdot 6 \mathrm{H}_{2} \mathrm{O}$ solution was used. This salt was reported to be stable to oxidation, and present a high solubility in water [41].

Significant differences $(p \leq 0.05)$ were found in the peroxide value of the lipids extracted with different extraction procedures (Table 1). According to the results, the peroxide value of lipids extracted from biscuits by different extraction methods is not always comparable. However, non significant differences were observed in the peroxide value of lipids extracted with the modified lipid extraction after acidic treatment and the direct solvent extraction method $(p>0.05)$. In addition, the peroxide value determined after the AACC [18] extraction procedure and its modification did not show any significant difference $(p>0.05)$.
On the other hand, significant differences were observed between the peroxide value determined after the conventional lipid extraction with acid treatment and the direct solvent extraction $(p \leq 0.05)$.

The lowest peroxide value was obtained when lipids were extracted by the Soxhlet extraction procedure $(p \leq 0.05)$, whereas the highest peroxide value was obtained after the conventional lipid extraction after acid treatment. Moreover, as previously explained, the highest amount of free fatty acids was obtained with this extraction method. As reported in previous works free fatty acids are more susceptible to oxidation [31]. These results suggest that the acid $\mathrm{pH}$ and the high temperature required in this extraction method lead to an easily oxidable lipid which present a higher peroxide value.

\section{Conclusion}

The use of isopropanol as solvent and the use of $\mathrm{Fe}\left(\mathrm{NH}_{4}\right)_{2}\left(\mathrm{SO}_{4}\right)_{2} \cdot 6 \mathrm{H}_{2} \mathrm{O}$ for the peroxide determination seem to be suitable modifications to the ferric thiocyanate assay.

All the extraction methods performed, except the AACC method, were found to be suitable for the determination of peroxides in low lipid biscuits. However, Soxhlet and direct solvent extraction methods led to less variation of the lipids structure and presented the higher extraction rate.

As direct solvent extraction provides a faster and simpler analysis, this method seems to be the most suitable for peroxide determination in low lipid biscuits.

\section{References}

1. M.L. Sudha, A.K. Srivastava, R. Vetrimani, K. Leelavathi, J. Agric. Food Chem. 48, 1322-1326 (2007)

2. S. Zahn, A. Forker, L. Krügel, H. Rohm, Food Sci. Technol. (LWT) 50, 695-701 (2013)

3. A. Forker, S. Zahn, H. Rohm, Food Bioprocess Technol. 5, 2497-2505 (2012)

4. H. Lingnert, J. Food Process. Preserv. 4, 219-233 (1980)

5. M. Bashash, N. Zamindar, M. Bolandi, J. Food Meas. Charact. 1, 5 (2014)

6. V. Reddy, A. Urooj, A. Kumar, Food Chem. 90, 317-321 (2005)

7. M. Estévez, S. Ventanas, R. Cava, J. Food Sci. 70, c427-c432 (2005)

8. P.I.M. Vicario Romero, R. Guillen Sans, M. Guzmán Chozas, Grasas Aceites 48, 96-102 (1997)

9. K. Miśkiewicz, E. Nebesny, J. Rosicka-Kaczmarek, G. Budryn, W. Krysiak, Grasas Aceites 64, 85-94 (2013)

10. G. Al-Bandak, V. Oreopoulou, J. Food Sci. Technol. 46, 290-296 (2011)

11. D.L. Mc Clements, E.A. Decker, in Quimica de los Alimentos, ed by S. Damodaran, K.L. Parkin, O. Fennema (Acribia, Zaragoza, 2008), pp. 155-214 
12. S. Mildner-Szkudlarz, R. Zawirska-Wojtasiak, W. Obuchowski, M. Gośliński, J. Food Sci. 74, S362-S370 (2009)

13. D. Mastrocola, M. Munari, J. Agric. Food Chem. 48, 3555-3559 (2000)

14. D. B. Min, J.M. Boff, in Food Analysis, ed. by S. Suzanne Nielsen (Kluwer Academic/Plenum Publishers, New York, 2003), pp 113-131

15. S. Chevallier, P. Colonna, A. Buléon, G. Della, Valle. J. Agric. Food Chem. 48, 1322-1326 (2000)

16. M. Patrignani, P.A. Conforti, C.E. Lupano, Int. J. Food Sci. Technol. 49, 1925-1931 (2014)

17. S.C. Santos, R.P. Guiné, A. Barros, J. Food Meas. Charact. 8, 105-112 (2014)

18. American Association of Cereal Chemists (AACC), Approved methods of the AACC. AACC method 30-10, 8th edn. (AACC, St. Paul, 1983)

19. M.D. Luque de Castro, F. Priego-Capote, J. Chromatogr. 1217, 2383-2389 (2010)

20. IDF-ISO, Milk fat. Determination of peroxide value. ISO 3976 IDF 74 (2006)

21. N. Nielsen, M. Timm-Heinrich, C. Jacobsen, J. Food Lipids 10, 35-50 (2003)

22. F. Priego-Capote, M.D. Luque de Castro, Talanta 65, 81-86 (2005)

23. P. Manirakiza, A. Covaci, P. Schepens, J. Food Compos. Anal. 14, 93-100 (2001)

24. T. Pérez-Palacios, J. Ruiz, D. Martín, E. Muriel, T. Antequera, Food Chem. 110, 1025-1029 (2008)

25. N.C. Shantha, G.E. Napolitano, Chromatogr. A. 624, 37-51 (1992)
26. J. Sherma, J. Chromatogr. A 880, 129-147 (2000)

27. B. Fuchs, R. Süß, K. Teuber, M. Eibisch, J. Schiller, J. Chromatogr. A 1218, 2754-2774 (2011)

28. Y. Zhou, Y. Xue, G.C. Chen, A.J. Zhang, Z.F. Chen, X. Liao, L.S. Ding, Food Chem. 141, 2098-2102 (2013)

29. V. Craige Trenerry, G. Akbaridoust, T. Plozza, S. Rochfort, W.J. Wales, M. Auldist, S. Ajlouni, Food Chem. 141, 1451-1460 (2013)

30. C. Ruiz-Samblás, L. Cuadros-Rodríguez, A. González-Casado, Talanta 83, 25-30 (2010)

31. W. Nawar, in Quimica de los Alimentos, ed. by S. Damodaran, K.L. Parkin, O. Fennema (Acribia, Zaragoza, 1993), pp. 157-274

32. American Oil Chemists' Society (AOCS), Official Methods and Recommended Practices of the American Oil Chemists' Society. AOAC Method Cd 8-53 (Champaign, 1997)

33. B. Barriuso, I. Astiasarán, D. Ansorena, Eur. Food Res. Technol. 236, 1-15 (2013)

34. N.C. Shantha, E.A. Decker, J. AOAC Int. 77, 421-424 (1994)

35. M.P. Richards, Y. Feng, Anal Biochem. 278, 232-235 (2000)

36. R. Bou, R. Codony, A. Tres, E.A. Decker a, F. Guardiola, Anal. Biochem. 377, 1-15 (2008)

37. B. Mihaljević, B. Katušin-Ražem, C. Ražem, Free Radic. Biol. Med. 21, 53-63 (1996)

38. A. Hara, N.S. Radin, Anal. Biochem. 90, 420-426 (1978)

39. I.M. Kolthoff, A.I. Medalia, Anal. Chem. 23, 595-603 (1951)

40. C.B. Kretschmer, J. Nowakowska, R. Wiebe, Ind. Eng. Chem. 38, 506-509 (1946)

41. A. Clavijo Díaz, Fundamentos de Química Analítica. Equilibrio iónico y análisis químico (Univ. Nacional de Colombia, 2002), p. 699 